\title{
Coping Skills and Burnout among Medical Officers in a Malaysian Tertiary Hospital
}

\author{
Nur Faizah Ali ${ }^{1}$, Nor Jannah Nasution Raduan', \\ Zaliha Ismail2, Salmi Razali ${ }^{1}$
}

\author{
1 Department of Psychiatry, Faculty of Medicine, \\ 2 Department of Public Health Medicine, Faculty of Medicine, \\ Universiti Teknologi MARA (UiTM), 47000 Sg. Buloh, Selangor Malaysia \\ faiess82@gmail.com, jannahraduan@gmail.com, drzie65@gmail.com, drsalmi@gmail.com
}

\begin{abstract}
Burnout among doctors is hazardous, leading to stress which results in poor decision making and exposure to medical errors. This study aims to improve the knowledge gap of the issues of burnout and coping skills among medical officers. This study is a cross-sectional study involving 250 medical officers using universal sampling. Of the total 250 participants, $63(25.2 \%)$ were burnout. The presence of burnout was significantly associated with dysfunctional coping skills $(t=-4.96 ; p$ $<0.001)$. Burnout is prevalent among medical officers. It is vital to take actions that can promote good mental health in the form of coping skills and resilience training.

Keywords: burnout; coping skills; doctors; medical

eISSN 2514-751X @ 2020 The Authors. Published for AMER ABRA cE-Bs by e-International Publishing House, Ltd., UK. This is an open-access article under the CC BY-NC-ND license (http://creativecommons.org/licenses/by$n c-n d / 4.0 /)$. Peer-review under responsibility of AMER (Association of Malaysian Environment-Behaviour Researchers), ABRA (Association of Behavioural Researchers on Asians) and cE-Bs (Centre for EnvironmentBehaviour Studies), Faculty of Architecture, Planning \& Surveying, Universiti Teknologi MARA, Malaysia. DOI: https://doi.org/10.21834/aje-bs.v5i15.357
\end{abstract}




\subsection{Introduction}

The prevalence of burnout is worrying. Almost one in every three physicians is experiencing burnout at any given time (Shanafelt et al., 2012). One of the reasons for such a high level of exhaustion was because of the long working hours. This scenario eventually causes severe stress and work-life imbalance (Shanafelt et al., 2012). Ineffective stress management may lead to various negative implications.

The most widely accepted concept of burnout was suggested by Maslach \& Jackson (1981) and elaborated further by Cordes \& Dougherty (1993) who described burnout in three dimensions: Emotional Exhaustion, Depersonalisation or Cynicism and low Personal Accomplishment. Emotional Exhaustion (EE) is the feeling of being emotionally overextended and exhausted caused by the working condition. Depersonalisation (DP) is the feeling of being detached and impersonal towards the people they encounter within one's work. Personal Accomplishment (PA) is a measure to assess the perception of competence and achievement when one works with people (Maslach, Jackson, \& Leiter, 1996; Schaufeli \& Enzmann, 1998).

A high level of burnout means high level of Emotional Exhaustion and Depersonalisation as well as low level of Personal Accomplishment. Burnout is known to have negative consequences at an individual level or during interaction with other people such as the patients, carers and other colleagues (Kumar, 2016). At the personal level, doctors who experience burnout might have impaired judgement and concentration, putting them at high risk of making a poor decision and making a mistake in their daily practice which can be of harm to the patients (Bernat, 2017). In regards of their relationship with the patients and carers as well as their colleagues, burnout doctors noted to be less empathetic towards their patients (Zenasni, 2012) and have a difficult relationship with the colleagues (Kumar, 2016).

Several scholars have suggested their ways of classifying coping skills. The widely used categorization of coping skills was introduced by Folkman (1984) and Folkman \& Lazarus (1980), who divided the coping skills into problem-focused and emotion-focused. Cooper, Katona, and Livingston (2008) introduced another type of coping; the dysfunctional coping skills. Researchers commonly use these three types of coping skills using the Brief COPE questionnaire (Carver, 1997).

In Malaysia, medical officers function as the main backbone of the routine clinical tasks that ensure the patients and family receive the highest standard of care. It is imperative to safeguard their wellbeing so that their personal physical and mental health are taken care of, apart from the efficient healthcare service delivery. To date, not many studies aimed to assess burnout and its association with coping skills among the medical officers to formulate appropriate stress management. Respective authorities can use the results from the studies to plan the evidence-based intervention for this group of people such as an initiative to address the problem efficiently, providing more workforce to a specific department or conducting coping skills training among the medical officers.

There is a gap in the understanding the level of burnout and coping skills among medical officers. Therefore, the objectives of this research are to determine the prevalence of burnout, to describe the domains of burnout and to identify the relationship between 
different types of coping skills and burnout among medical officers working in a tertiary hospital in Malaysia.

\subsection{Literature Review}

\subsection{Definition and Assessment of Burnout}

The interest of the nature of people's behaviour at work and perception of their wellbeing has been of great importance in research lately (Green, Felstead, \& Gallie, 2013; Krueger, 2007). The focus is so great that it becomes the theme of the World Mental Health Day 2017 - Mental Health in The Workplace. This initiative shows that happiness and being healthy, physically and emotionally at work is essential (Danna \& Griffin, 1999). This concept is achievable if one has a positive experience with the job such as being satisfied with the work, right attachment and involvement (Allen, Herst, Bruck, \& Sutton, 2000; Krueger, 2007). If someone's working condition is stressful, it can cause negative consequences such as uncontrollable tension, depression, alienation from work and subsequently burnout (Krueger, 2007).

In the year 1974 and 1996, a psychiatrist and a clinical psychologist described burnout in their published papers about burnout (Freudenberger, 1974; Maslach et al., 1996). Since then, more studies came along discussing the definition, factors associated with it, and how to manage burnout. Freudenberger (1974) focused more on the clinical aspect as to how to assess burnout, how to prevent it from happening as well as focusing on the possible treatment options. Other researchers, on the other hand, focused more on the theory of burnout and evidence-based (Maslach \& Jackson, 1981; Maslach, Leiter, \& Schaufeli, 2008).

There was also debate as to whether to define burnout as a multidimensional or unidimensional construct (Brenninkmeijer \& Vanyperen, 2003). The earlier works suggested three dimensions of burnout; Emotional Exhaustion, Depersonalisation and Personal Accomplishment (Maslach \& Jackson, 1981; Maslach et al., 1996). Although the multidimensional theory of burnout becomes the primary approach in burnout studies, more people found the need to look at it in a unidimensional approach. It is useful, especially if people are trying to study the complicated relationship between burnout and other variables.

There are a few different questionnaires to assess burnout. Three of the widely used are the Maslach Burnout Inventory (MBI), Oldenburg Burnout Inventory and Copenhagen Burnout Inventory. Each of the questionnaires has its advantages or disadvantages. The Maslach Burnout Inventory is the most widely used, and it measures three widely accepted dimensions of burnout; Emotional Exhaustion, Depersonalisation and Personal Accomplishment. It is because it has excellent psychometric properties measuring the subscales (Greenglass, Burke, \& Ondrack, 1990; Maslach \& Jackson, 1981)

The Oldenburg Burnout inventory measures the two dimensions of burnout (Emotional Exhaustion and Depersonalisation) while the Copenhagen Burnout Inventory only measures the Emotional Exhaustion part. In Malaysia, researchers who investigated 
burnout mainly used Maslach Burnout Inventory and the Copenhagen Burnout Inventory (Chin et al., 2016; Sabki \& Zainal, 2015).

\subsection{Burnout and Medical Doctors}

Burnout is associated with diminished efficiency and high turnover rate as well as causing reduced clients' satisfaction (Pakenham \& Stafford-Brown, 2012). In Malaysia, a study was done in Universiti Kebangsaan Malaysia Medical Centre (UKMMC) demonstrated that any element that contributed to job stress such as highly demanding tasks, increased workload and the conflict between work and social/family life could cause psychological distress. Psychological distress can potentially lead to burnout among doctors (Tan, Jong, Jamaludin, Jamaludin, \& Shah, 2013).

Although burnout can affect people from all different kinds of job scope, the work related to human services and caring for other people such as teacher, nurses and doctors are of higher risk (Roslan, S., Sharifah, \& Thirumalai, 2012). Doctors have a higher susceptibility for burnout, probably due to the nature of their training and work.

Globally, there are substantial studies that address this predicament. The studies suggested that doctors are more vocal in expressing their struggle and rights (Lee, Medford, \& Halim, 2015). This action was through various platforms such as discussions with non-governmental organisations (NGOs) and the policymakers regarding multiple issues related to burnout among the doctors. In the United States, a large study involving 7288 doctors, showed that $45.8 \%$ of them manifested symptoms of burnout, especially those who worked in family medicine, general internal medicine and emergency medicine. One of the reasons for such a high level of burnout was because of the long working hours, which eventually cause the imbalance of work and life (Shanafelt et al., 2012). In other countries such as European countries, Hong Kong, China and Africa, the prevalence of burnout were reported to be between $12 \%$, to $31.4 \%$ (Sirsawy, Steinberg, \& Raubenheimer, 2016; Siu, Yuen, \& Cheung, 2012; Soler et al., 2008; Wu et al., 2013).

\subsection{Coping Skills and Burnout}

Coping and stress cannot be separated, and both of the concepts are related to change. Stress in itself is the change of the equilibrium in a person's life, and by utilising coping skills, the person can change this disequilibrium (Folkman \& Lazarus, 1985). It is done by the constant cognitive change and adaptation of the behaviour of the person who tries to manage the situation where the excess internal or the external demands becomes too much (Folkman \& Lazarus, 1980). The excess stimuli or the stressful situation can be from current or past experiences. Both can trigger the reaction of coping (Goretti, Zipoli, Portaccio, Razzolini, \& Amato, 2010).

An individual most often uses a combination of more than one type of coping. The problem-focused coping skills are employed when one seeks to solve a problem and modify the actual reason that causes stress in the first place (Yusoff, Ying Jie, \& Esa, 2011). In situations where the issues do not have any specific solution and need endurance, the emotion-focused coping skills should be best employed (Folkman, 1984; Folkman \& Lazarus, 1980). As for dysfunctional coping skills, it is the type of coping that can make a 
person have more difficulty in overcoming his/her problem and hence, the escalation of stress occurs.

A meta-analysis done by a group of researchers stated that when comparing two groups of doctors from different continents (the United States vs Europe), the group that used problem-focused showed lower Emotional Exhaustion level (Lee et al., 2013). However, depending solely on problem-focused coping can be counterproductive for the doctors because not all problem encountered during their practice can be solved (Sotile \& O'Sotile, 2003).

Other concepts used to describe the construct of coping include 'engagement vs disengagement', 'control vs escape', 'behavioural vs cognitive coping' and 'social vs solitary' and many others (Compas, Connor-Smith, Saltzman, Thomsen, \& Wadsworth, 2001; Latack, J. C., \& Havlovic, 1992).

\subsection{Methodology}

This study is a cross-sectional study involving medical officers in one of the tertiary hospitals in Klang Valley, Malaysia using a universal sampling method.

The researcher approached a total of 408 medical officers (clinical and non-clinical) during a weekly Hospital Continuous Medical Education (CME) and departmental CME from March until May 2017. The researcher explained the participants' information sheet and the study risk and benefit. Medical officers who gave written informed consent recruited for the study. A set of questionnaires provided before the CMEs and collected after the CMEs. Those who had not finished answering the questions, they were followed up at the departmental level. Those who were not in the CMEs (for example in operation theatre, on leave, etc.) did not take part.

Inclusion criteria include medical officers registered in the hospital database at the time of the study, aged 18 and above and who were able to understand, read and communicate in English or Bahasa Malaysia. Exclusion criteria include medical officers based in the studied hospital but at the time of the study were in other hospitals or health facilities for continuous learning, and who have a previous history of psychiatric illness.

Maslach Burnout Inventory (MBI-HSS) was used to measure burnout, and the operationalized definition of burnout in this study follows description used by former groups of researchers; Brenninkmeijer \& Vanyperen (2003); Sabki \& Zainal (2015) as well as Maslach et al. (1996). Burnout defined by these researchers as a "high" score $(\geq 75$ th percentile) of the EE total score plus the overall score of DP. Assessment of the severity of three dimensions of burnout; EE, DP and PA were done to determine low, moderate and high levels of each burnout dimensions. Cronbach's alpha for the EE, DP and PA in the present study were $0.880,0.790$, and 0.735 , respectively. Coping skills were measured using the Brief COPE, which consists of 28 items. The three types of coping skills were: i) problem-focused, ii) emotion-focused coping, and iii) dysfunctional coping (Cooper et al., 2008; Folkman, 1984). All questionnaires distributed to the participants were according to their preference of either Malay or English versions.

Ethical approval was from the Ethical Board of Research Committee of Universiti 
Teknologi MARA (UiTM) and the National Medical Research and Ethics Committee (MREC) of the Ministry of Health (MOH), Malaysia via the National Medical Research Registry (NMRR).

All data analysis performed using International Business Machines (IBM®) Statistical Package for Social Sciences (SPSS $®$ version 24) for Window 10. Descriptive statistics used to describe sociodemographic factors, burnout, and coping skills. Bivariate analysis (chi-square test and independent t-test) and multivariate analysis (linear regression) used to study the prevalence of burnout, coping skills and the association between the two factors.

\subsection{Findings}

A total of 390 questionnaires distributed. Of the total, 255 participants consented and submitted their answered questionnaires. The response rate was $65.38 \%$. Five questionnaires rejected due to incompletion.

There were more female than male medical officers ( $32 \%$ male and $68 \%$ female) with the mean age of $30.37 \pm 2.80$ years. More than half were Malays $(135 ; 54 \%)$ and married $(145 ; 58 \%)$. About two-thirds of the medical officers had no children (160; $64 \%)$. In terms of the cluster of the department, the medical and surgical clusters had about the same number of medical officers which was significantly higher than the ones on laboratory medicine and administration cluster. The mean duration of service in months as a medical officer was $54.3 \pm 42.39$. 81 (32.4\%) of the medical officers were at the time of study undertaking postgraduate training (refer Table 1).

Table 1. The socio-demographic factors of the medical officers

\begin{tabular}{|c|c|c|c|}
\hline Variable & & Frequency (\%) & Mean (SD) \\
\hline \multicolumn{3}{|c|}{ Age (years) } & $30.37(2.80)$ \\
\hline \multicolumn{4}{|c|}{ Gender } \\
\hline & Male & $80(32)$ & \\
\hline & Female & $170(68)$ & \\
\hline \multicolumn{4}{|c|}{ Ethnicity } \\
\hline \multirow{2}{*}{$\bullet$} & Malay & $135(54)$ & \\
\hline & Chinese & $59(23.6)$ & \\
\hline & Indian & $53(21.2)$ & \\
\hline \multicolumn{4}{|c|}{ Others } \\
\hline \multicolumn{4}{|c|}{ Marital status } \\
\hline \multirow{2}{*}{\multicolumn{4}{|c|}{ - $\quad$ Single }} \\
\hline & & $145(58.0)$ & \\
\hline \multicolumn{4}{|c|}{ No. of children } \\
\hline \multicolumn{4}{|c|}{ - $\quad 0$} \\
\hline \multicolumn{4}{|c|}{ - $\quad 1-2$} \\
\hline \multicolumn{4}{|c|}{ - $\quad 3-4$} \\
\hline \multirow{2}{*}{\multicolumn{4}{|c|}{ Department $^{\text {5-6 }}$}} \\
\hline & & & \\
\hline & Administration & $7(2.8)$ & \\
\hline$\bullet$ & Medical cluster & $119(47.6)$ & \\
\hline
\end{tabular}


- $\quad$ Surgical cluster $\quad 116(46.4)$

- $\quad$ Medical sciences $8(3.2)$

Duration working as MO (months)

$54.3(42.385)$

Specialist training program

- $\mathrm{Yes}$

- No
$81(32.4)$

$169(67.6)$

This study found the cut-off point for a total score of the presence of burnout (i.e. level of Emotional Exhaustion and Depersonalisation more than 75 percentiles) was at $\geq 41$ (refer Table 3).

Table 3. Scores of the MBI-HSS and its sub-scales

\begin{tabular}{|c|c|c|c|c|c|c|c|c|c|}
\hline $\begin{array}{c}\text { Dimensi } \\
\text { ons }\end{array}$ & $\begin{array}{l}\mathrm{N} \\
\text { ite } \\
\mathrm{ms}\end{array}$ & $\begin{array}{l}\text { Mean } \\
\text { (SD) }\end{array}$ & $\begin{array}{c}\text { Ran } \\
\text { ge }\end{array}$ & $\begin{array}{c}25^{\text {th }} \\
\text { percenti } \\
\text { les }\end{array}$ & $\begin{array}{c}50^{\text {th }} \\
\text { percenti } \\
\text { les }\end{array}$ & $\begin{array}{c}75^{\text {th }} \\
\text { percenti } \\
\text { les }\end{array}$ & $\begin{array}{l}\text { Low } \\
n(\%)\end{array}$ & $\begin{array}{c}\text { Moder } \\
\text { ate } \\
\mathrm{n}(\%)\end{array}$ & $\begin{array}{l}\text { High } \\
\mathrm{n}(\%)\end{array}$ \\
\hline $\begin{array}{c}\text { EE } \\
\text { DP } \\
\text { PA } \\
\text { Presenc } \\
\text { e of } \\
\text { burnout } \\
\text { (EE+DP) }\end{array}$ & $\begin{array}{c}9 \\
5 \\
8 \\
14\end{array}$ & $\begin{array}{c}23.41(10 . \\
66) \\
8.18 \\
(5.95) \\
31.38(7.4 \\
24) \\
31.59(15 . \\
24)\end{array}$ & $\begin{array}{c}2-51 \\
0-30 \\
14- \\
48 \\
4-77\end{array}$ & $\begin{array}{c}16.0 \\
4.0 \\
26.0 \\
20.0\end{array}$ & $\begin{array}{c}32.0 \\
7.0 \\
31.0 \\
32.0\end{array}$ & $\begin{array}{l}31.0 \\
12.0 \\
37.3 \\
41.0\end{array}$ & $\begin{array}{c}67(26 . \\
8) \\
118(47 \\
.2) \\
128(51 \\
.2)\end{array}$ & $\begin{array}{c}87(34 . \\
8) \\
77(30 . \\
8) \\
77(30 . \\
8)\end{array}$ & $\begin{array}{c}96(38 . \\
4) \\
55(22 . \\
0) \\
45(18 . \\
0)\end{array}$ \\
\hline
\end{tabular}

Prevalence of burnout among the medical officers in a tertiary hospital in Malaysia was $25.2 \%(n=63)$ (refer to Figure 1). In the EE dimension, more than a third (38.4\%) of medical officers scored high. For the DP dimension, only $22 \%$ reported high score, and for PA dimension, the majority (51.2\%) scored low (refer Figures 2 to 4 ).

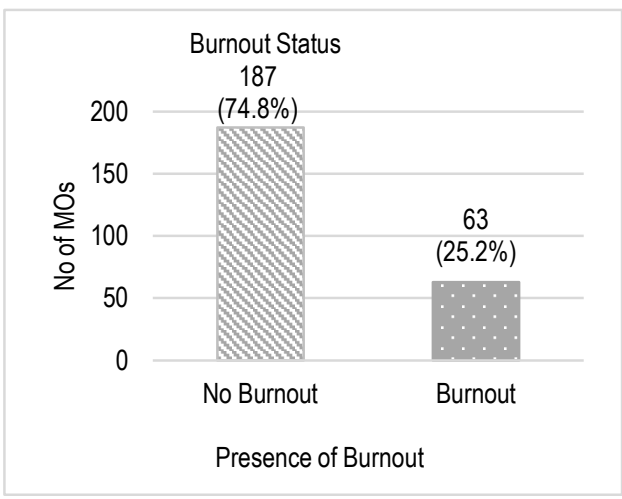

Figure 1: The presence of burnout 


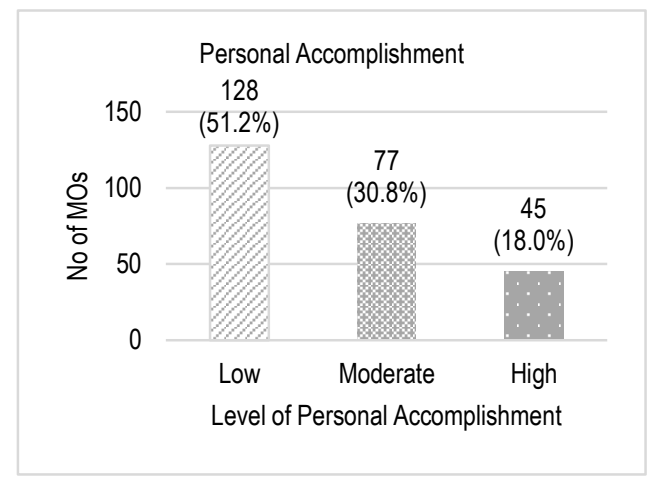

Figure 2: Level of Emotional Exhaustion

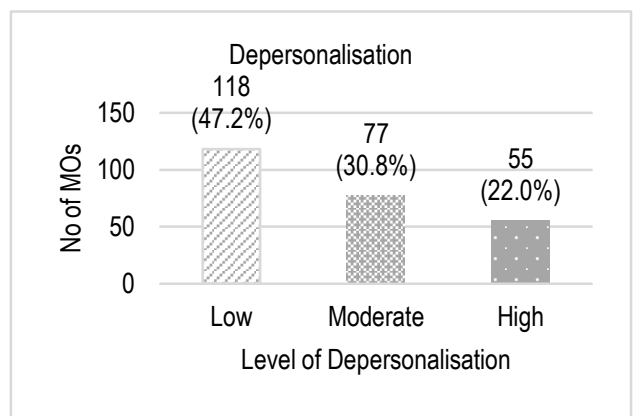

Figure 3: Level of Depersonalisation

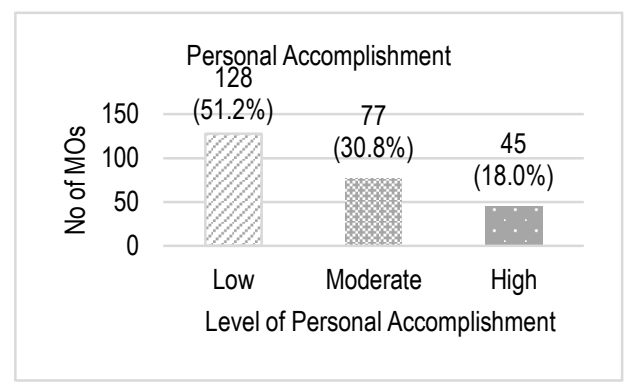

Figure 4: Level of Personal Accomplishment

There was a significant difference in the mean score of dysfunctional coping among those having burnout and no burnout group $(t=-4.96, p=<0.001)$ (refer Table 4). 
Table 4. The Association between coping skills and burnout

\begin{tabular}{|c|c|c|c|c|c|c|}
\hline \multirow{2}{*}{ Method } & \multirow{2}{*}{$\begin{array}{l}\text { Mean } \\
\text { (SD) }\end{array}$} & \multirow{2}{*}{$\begin{array}{l}\text { Types of coping } \\
\text { skills }\end{array}$} & \multicolumn{2}{|c|}{ Mean (SD) } & \multirow{2}{*}{$\begin{array}{c}t \\
\text { statistic(df) }\end{array}$} & \multirow{2}{*}{$\begin{array}{c}p \\
\text { value }^{*}\end{array}$} \\
\hline & & & Burnout & No Burnout & & \\
\hline Active coping & $5.76(1.36)$ & \multirow{3}{*}{ Problem focused } & \multirow{3}{*}{$16.16(3.42)$} & \multirow{3}{*}{$16.19(2.88)$} & \multirow{3}{*}{$0.07(248)$} & \multirow{3}{*}{0.95} \\
\hline Instrumental support & $5.36(1.60)$ & & & & & \\
\hline Planning & $5.83(1.34)$ & & & & & \\
\hline Emotional support & $5.46(1.76)$ & \multirow{5}{*}{ Emotion focused } & \multirow{5}{*}{$26.90(4.77)$} & \multirow{5}{*}{$27.93(5.16)$} & \multirow{5}{*}{$1.39(248)$} & \multirow{5}{*}{0.17} \\
\hline Positive reinterpretation & $5.88(1.34)$ & & & & & \\
\hline Humour & $4.28(1.72)$ & & & & & \\
\hline Acceptance & $5.99(1.33)$ & & & & & \\
\hline Religion & $6.06(1.80)$ & & & & & \\
\hline Mental disengagement & $5.44(1.37)$ & \multirow{6}{*}{ Dysfunctional } & \multirow{6}{*}{$24.43(4.52)$} & \multirow{6}{*}{$21.42(4.04)$} & \multirow{6}{*}{$-4.96(248)$} & \multirow{6}{*}{${ }^{*}<0.001$} \\
\hline Denial & $2.72(1.09)$ & & & & & \\
\hline Substance abuse & $2.20(0.82)$ & & & & & \\
\hline $\begin{array}{l}\text { Behavioural } \\
\text { disengagement }\end{array}$ & $2.98(1.20)$ & & & & & \\
\hline Venting of emotion & $4.59(1.41)$ & & & & & \\
\hline Self-blame & $4.25(1.53)$ & & & & & \\
\hline
\end{tabular}

Multivariate analysis of coping skills and burnout concluded that medical officers who adopt the dysfunctional coping skills have 1.1 times the odds of having burnout than those who do not. Medical officers who employed emotion-focused are $8 \%$ less likely to get burnout which can be a protective factor (refer Table 5)

Table 5. Multivariate analysis of associated factors with burnout

\begin{tabular}{cccccc}
\hline Variables & $\mathrm{B}$ & $\mathrm{SE}$ & $\begin{array}{c}\text { Adjusted } \mathrm{OR} \\
(95 \% \mathrm{Cl})\end{array}$ & $\begin{array}{c}\text { Wald statistics } \\
(\mathrm{df})\end{array}$ & $P_{\text {-value }}$ \\
\hline Emotion-focused coping skills & -0.82 & 0.03 & $0.92(0.86,0.98)$ & $6.08(1)$ & 0.014 \\
\hline Dysfunctional coping skills & 0.19 & 0.04 & $1.2(1.12,1.30)$ & $22.75(1)$ & $<0.001$ \\
\hline
\end{tabular}

\subsection{Discussion}

It was known for several decades that doctors have worryingly high rates of suicide and depression when compared with the general population (Devi, 2011). Hence it is pivotal for stress and burnout among doctors to be prevented, and early intervention offered to address this issue before these disturbances turned into more serious mental illnesses. Our study provides a few valuable points to managing stress and burnout among this group of professionals. We found a significant percentage of burnout among the medical officers (25.2\%) and its main contributing factors; being single, having psychological distress. The rate of burnout we found is consistent with a study in a public hospital in South Africa which documented $26.3 \%$ of burnout among the 205 number of participants (Sirsawy et al., 2016). Both study settings were public hospitals. In a more well-resourced country such as the Netherlands, Prins et al., (2010), who investigated a more significant number of respondents (5140 respondents), the rate of burnout was similar. In contrary, Shanafelt et al. (2012), Wu et al. (2013), found a higher prevalence of burnout compared to our findings 
which may be due to bigger sample size.

However, a study in Europe by Soler et al. (2008) and another in Yemen by Al-Dubai \& Rampal (2010) showed much lower prevalence rate compared to the current study. It is worth to note that the different studies in burnout used different definition to identify the presence of burnout, for example, taking into consideration only the Emotional Exhaustion as the determinant of burnout (Aiken, Clarke, Sloane, \& Sochalski, 2002). The differences may be one of the factors contributing to discrepancies in the rate of prevalence.

The burnout prevalence of medical officers is similar to that of doctors going through housemanship (Sabki \& Zainal, 2015). However, studies among medical students showed as high as $67.9 \%$ of burnout (Al-Dubai et al., 2011; Chin et al., 2016), much higher compared to medical officers. This finding could be due to the difference in the dynamics of being students compared to those who already started working.

Medical officers have more responsibilities in clinical practice, administrative work, and undergo training to be specialists with additional commitments and expectations. At this stage, medical officers need to adjust to the new working time, where they work at longer hours during on-call contrary to the working system of Houseman's Flexi Hour Shift System, during the internship, which found to reduce job-related stress (Thillainathan, 2011). This is the first study exploring the association between coping skills and burnout among the medical officers in Malaysia.

Using an effective coping strategy is crucial for medical officers to manage their stress and preventing burnout. Our study indicated that emotion-focused coping skills are protective against burnout, whereby medical officers who employed emotion coping skills were $8 \%$ less likely to have burnout. It helps the medical officers to cope in situations where no specific solution is available. This type of coping serves to alleviate distress by minimizing, reducing, or preventing, the emotional components of a stressor. Emotionfocused coping skills may include seeking emotional support, positive reinterpretation, acceptance, denial, and turning to religion (Cooper et al., 2008; Folkman, 1984). Another positive emotion-focused coping that is used to reduce burnout include talking or writing about own emotions through therapy or journaling, mindful meditation, or distraction with other activities. Through this type of coping, the stress in their internal psyche may be channelled out to prevent burnout.

Dysfunctional coping skills found to be significantly associated with burnout in this study. This finding does not come as a surprise because of previous studies showing dysfunctional coping skill as the cause of distress and a source of stress (Cooper et al., 2006; Yusoff et al., 2011). It is essential to note the possibility of burnout medical officers in this study, not adequately trained in healthy coping skills in dealing with their daily stress. These medical officers highly likely adopt the dysfunctional coping style due to lack of experience. Many of them are still in their early career path and had not developed the maturity to process their own emotion and behaviour. The lack of proper training of healthy coping skill in the formal curriculum in Medicine too can serve as the contributing factor. Only recently, such curriculum introduced in most medical school in the United States (Shanafelt \& Dyrbye, 2012). In other places, no specific course incorporated in the curriculum that promotes self-health and wellness, although these skills are vital to cultivate 
the behaviour that ensures resilience throughout their medical career.

There are several approaches available in addressing the issue of burnout. A recent guide from the World Economic Forum suggests that interventions should take a 3-pronged approach: to protect mental health by reducing work-related risk factors; to promote mental health by developing the positive aspects of work and the strength of employees, and to address mental health problems regardless of cause. Periodical psychological assessment, particularly the level of burnout among doctors, should be incorporated to protect their best interest. Screening the doctors with the burnout tools should be feasible, and results need to be accessible by specific centres, for example, the hospital, universities or the health clinic. This action can enable early interventions.

Authorities handling the welfare of doctors should look into incorporating the training of self-health and useful coping strategies in the curriculum throughout the medical practice. Short courses of maintaining good physical and psychological health are also vital. Methods such as tackling the specific issues at the individual level (for example family history, workload, number of on calls, monthly salary, financial difficulties), the environmental level (for instance conducive working environment) and the organizational level (for example types of leadership) need to be encouraged. These efforts need to be supported by the government or by the national blue ocean strategy (NBOS) from the financial and expertise point of view.

There were a few areas of improvement in this study. First, the study design itself that is the cross-sectional and sampling method using the universal (non-probability) sampling. Second, participants in this study were limited to the involvement of medical officers in one public hospital in Malaysia and did not represent the whole population of medical officers in Malaysia. No diagnostic tool used. Lastly, medical officers who were rushing to complete their daily task might not take their time to answer the question carefully. Among recommendations for future study include using longitudinal cohort study to provide a better perspective of the issues of burnout and gives better clarification on information, stronger findings and associations between coping skills and burnout amongst the medical officers and using probability sampling method such as randomized sampling, to improve the generalizability. Multi-centre studies on medical officers involving rural area as well as other settings such as medical-related research centres, health clinic and private practices/hospital could be conducted throughout Malaysia to have a generalised projection.

\subsection{Conclusions}

Being a doctor is a profession of nobility and highly respected by the community. However, it comes with significant responsibilities and demands, not only to the individual but also from the people close to them. Due to the nature of the work and how doctors were trained, they are in constant exposure to stress and distress, which can eventually lead to burnout if their wellbeing not being taken seriously.

Burnout is also prevalent among medical officers, not just among medical students or junior doctors. This issue needs to be seriously addressed because it will affect healthcare 
services negatively. Dysfunctional coping skills contribute to burnout while emotionfocused coping skills are protective against burnout. To make our medical officers more resilient in their career, the identification of dysfunctional coping skills and replacing them with healthier styles of managing stress is critical. Screening the medical officers with the burnout tools should be feasible, and results need to be accessible by the specific centres, for example the hospital, universities or the health clinic.

Furthermore, medical officers are encouraged to manage their problems or stress through healthy ways of coping. Knowledge of mental health awareness, resilience competency training, mindfulness training, self-compassion, support group and other intervention programs are beneficial to prevent burnout. In the future, further studies on various effective intervention to overcome this problem are very much needed.

\section{Acknowledgement}

We would like to extend our appreciation to the Ministry of Health, Malaysia and Universiti Teknologi MARA for their involvement and cooperation to make this study a success.

\section{References}

Aiken, L. H., Clarke, S. P., Sloane, D. M., \& Sochalski, J. (2002). Hospital Nurse Staffing and Patient Mortality , Nurse Burnout , and Job Dissatisfaction. Journal of American Medical Association, 288(16), 1987-1993.

Al-Dubai, S. A. R., Al-Naggar, R., AL-Shagga, M., \& Rampal, K. (2011). Stress and Coping Strategies of Students in a Medical Faculty in Malaysia. Malaysian Journal of Medical Science, 18(3), 57-64.

Al-Dubai, S. A. R., \& Rampal, K. G. (2010). Prevalence and associated factors of burnout among doctors in Yemen. Journal of Occupational Health, 52, 58-65. https://doi.org/10.1539/joh.08030

Allen, T. D., Herst, D. E. L., Bruck, C. S., \& Sutton, M. (2000). Consequences Associated With Work-to-Family Conflict: A Review and Agenda for Future Research. Journal of Occupational Health Psychology, 5(2), 278-308. https://doi.org/10.1037//1076-899B.5.2.278

Bernat, J. L. (2017). How Can Neurologists Avoid Burnout? Neurology, 88, 1-3. https://doi.org/10.1212/WNL.0000000000003648

Brenninkmeijer, V., \& Vanyperen, N. (2003). How To Conduct Research on Burnout: Advantages and Disadvantages of a Unidimensional Approach in Burnout Research. Occup Environ Med, 60, 16-20.

Carver, C. S. (1997). You Want to Measure Coping but Your Protocol Too Long: Consider the BRIEF Cope. International Journal of Behavioral Medicine, 4(1), 92-100. https://doi.org/10.1207/s15327558ijbm0401_6

Chin, R., Chua, Y. Y., Chu, M. N., Mahadi, N., Yusoff, M., Wong, M., \& Lee, Y. Y. (

2016). Prevalence of Burnout among Universiti Sains Malaysia Medical Students. Education in Medicine Journal, 8(3), 61-74. https://doi.org/10.5959/eimj.v8i3.454 
Compas, B. E., Connor-Smith, J. K., Saltzman, H., Thomsen, A. H., \& Wadsworth, M. E. (2001). Coping With Stress During Childhood and Adolescence: Problems, Progress And Potential in Theory and Research. Psychological Bulletin, 127, 87-127. https://doi.org/10.1037//0033-2909.127.1.87

Cooper, C., Katona, C., \& Livingston, G. (2008). Validity and Reliability of the Brief COPE in Carers of People With Dementia. The Journal of Nervous and Mental Disease, 196(11), 838-843. https://doi.org/10.1097/NMD.0b013e31818b504c

Cooper, C., Katona, C., Orrell, M., \& Livingston, G. (2006). Coping Strategies and Anxiety in Caregivers of People with Alzheimer's Disease: The LASER-AD Study. Journal of Affective Disorders, 90, 15-20. https://doi.org/10.1016/j.jad.2005.08.017

Cordes, C. L., \& Dougherty, T. W. (1993). A Review and an Integration on Job Burnout. Academy of Management Review, 18(4), 621-656.

Danna, K., \& Griffin, R. W. (1999). Health and Well-Being in the Workplace: A Review and Synthesis of the Literature. Journal of Management, 25(3), 357-384. https://doi.org/10.1177/014920639902500305

Devi, S. (2011). Doctors in Distress. The Lancet, 377(9764), 454-455. https://doi.org/https://doi.org/10.1016/S0140-6736(11)60145-1

Folkman, S. (1984). Personal Control and Stress and Coping Processes: A Theoretical Analysis. Journal of Personality and Social Psychology, 46(4), 839-852. https://doi.org/10.1037/0022-3514.46.4.839

Folkman, S., \& Lazarus, R. S. (1980). An Analysis of Coping in a Middle-Aged Community Sample. Journal of Health and Social Behavior, 21(3), 219-239.

Folkman, S., \& Lazarus, R. S. (1985). If It Changes It Must Be A Process: Study of Emotion and Coping During Three Stages of A College Examination. Journal of Personality and Social Psychology, 48(1), 150-170. https://doi.org/10.1037/0022-3514.48.1.150

Freudenberger, H. J. (1974). Staff Burn-Out. Journal of Social Issues, 30(1), 159-165. https://doi.org/10.1111/j.1540-4560.1974.tb00706.x

Goretti, B., Zipoli, V., Portaccio, E., Razzolini, L., \& Amato, M. P. (2010). Coping Strategies, Cognitive Impairment , Psychological Variables and Their Relationship with Quality of Life in Multiple Sclerosis. Neurological Sciences, 31(2), 227-230. https://doi.org/10.1007/s10072-010-0372-8

Green, F., Felstead, A., \& Gallie, D. et al. (2013). Job-related Well-being in Britain: First findings from The Skills And Employment Survey 2012. London: Centre for Learning and Life Chances in Knowledge Economies and Societies, Institute of Education. London. Retrieved from http://www.cardiff.ac.uk/_data/assets/pdf_file/0003/118659/6.-Job-related-Well-being-in-Britain-mini-report.pdf

Greenglass, E. R., Burke, R. J., \& Ondrack, M. (1990). A Gender-role Perspective of Coping and Burnout. Applied Psychology: An International Journal, 39(1), 5-27.

Krueger, M. (2007). Four Areas of Support for Child and Youth Care Workers. The Journal of Contemporary Social Services, 88, 233-240.

Kumar, S. (2016). Burnout and Doctors: Prevalence, Prevention and Intervention. Healthcare, 4(37), 1-9. https://doi.org/10.3390/healthcare4030037

Latack, J. C., \& Havlovic, S. J. (1992). Coping with Job Stress: A Conceptual Evaluation Framework for Coping Measures. Journal of Organizational Behavior, 13, 479-508. 
Ali, N.F.,et.al. / Asian Journal of Environment-Behaviour Studies (ajE-Bs), 5(15) Jan / Apr 2020 (pp.1-15)

Lee, R. T., Seo, B., Hladkyj, S., Lovell, B. L., \& Schwartzmann, L. (2013). Correlates of Physician Burnout Across Regions and Specialties : A Meta-analysis. Human Resources for Health, 11(48), 1-16.

Lee, Y. Y., Medford, A., \& Halim, A. S. (2015). Burnout in Physicians. Journal of the Royal College of Physicians of Edinburgh, 45, 104-107. https://doi.org/10.4997/JRCPE.2015.203

Maslach, C., \& Jackson, S. (1981). The measurement of experienced Burnout. Journal of Occupational Behavior, 2, 99-113. https://doi.org/10.1002/job.4030020205

Maslach, C., Jackson, S. E., \& Leiter, M. P. (1996). Maslach Burnout Inventory Manual (3rd ed.). California, CA: Consulting Psychologists.

Maslach, C., Leiter, M. P., \& Schaufeli, W. (2008). The Oxford Handbook of Organizational Well Being. (Susan Cartwright and Cary L. Cooper, Ed.). Oxford University Press. https://doi.org/10.1093/oxfordhb/9780199211913.003.0005

Pakenham, K. I., \& Stafford-Brown, J. (2012). Stress in Clinical Psychology Trainees: A Review of Current Research and Future Directions. Australian Psychologist, 47, 147-155. https://doi.org/10.1111/j.17429544.2012.00070.x

Peltzer, K., Mashego, T., \& Mabeba, M. (2003). Short Communication : Occupational Stress and Burnout Among South African Medical Practitioners. Stress and Health, 19, 275-280. https://doi.org/10.1002/smi.982

Prins, J. T., Hoekstra-Weebers, J. E. H. M., Gazendam-Donofrio, S. M., Dillingh, G. S., Bakker, A. B., Huisman, M., ... Van Der Heijden, F. M. M. A. (2010). Burnout and Engagement Among Resident Doctors in the Netherlands: A National Study. Medical Education, 44, 236-247. https://doi.org/10.1111/j.1365-2923.2009.03590.x

Roslan, S., Sharifah, M. N., \& Thirumalai, V. N. (2012). The Burnout Phenomenon : Changes in Psychosocial Profiles of Secondary School Teachers. Journal of Social Science and Humanities, 20(S), 157-174.

Sabki, Z., \& Zainal, N. (2015). Exploring Burnout Among Malaysian Junior Doctors Using the Abbreviated Maslach Burnout Inventory. Malaysian Journal of Psychiatry, 24(1), 1-10.

Schaufeli, W., \& Enzmann, D. (1998). The burnout compan- ion to study and practice: a critical analysis. London: Taylor \& Francis.

Shanafelt, T. D., Boone, S., Tan, L., Dyrbye, L. N., Sotile, W., Satele, D., ... Oreskovich, M. R. (2012). Burnout and satisfaction with work-life balance among US physicians relative to the general US population. Archives of Internal Medicine, 172(18), 1377-1385. https://doi.org/10.1001/archinternmed.2012.3199

Shanafelt, T., \& Dyrbye, L. (2012). Oncologist Burnout: Causes, Consequences, and Responses. Journal of Clinical Oncology, 30(11), 1235-1241. https://doi.org/10.1200/JC0.2011.39.7380

Sirsawy, U., Steinberg, W. J., \& Raubenheimer, J. E. (2016). Levels of Burnout Among Registrars and Medical Officers Working at Bloemfontein Public Healthcare Facilities in 2013. South African Family Practice, 1(1), 1-6. https://doi.org/10.1080/20786190.2016.1198088

Siu, C. F. Y., Yuen, S. K., \& Cheung, A. (2012). Burnout Among Public Doctors in Hong Kong : Cross-Sectional Survey. Hong Kong Med Journal, 18, 186-194.

Soler, K. J., Yaman, H., Esteva, M., Dobbs, F., Desgranges, P., Moreau, A., ... Sa Azeredo, Z. D. A. (2008). Burnout in European Family Doctors : The EGPRN Study. Family Practice-An International Journal, 25(4), 245265. https://doi.org/10.1093/fampra/cmn038 
Sotile, W. M., \& O'Sotile, M. (2003). Beyond Physician Burnout: Keys to Effective Emotional Management. Journal of Medical Practice Management, 18(6), 315-318.

Tan, M. K., Jong, S. C., Jamaludin, N. A., Jamaludin, N. S., \& Shah, S. A. (2013). Physician, Heal Thyself : The Paradox of Anxiety Amongst House Officers and Work in a Teaching Hospital. Asia Pasific Psychiatry, 5, 74-81. https://doi.org/10.1111/appy.12048

Thillainathan, S. (2011). Implementation of Flexi Hours for House Officers. Retrieved July 1, 2017, from www.moh.gov.my/attachments/8065

Wu, H., Liu, L., Wang, Y., Gao, F., Zhao, X., \& Wang, L. (2013). Factors Associated With Burnout Among Chinese Hospital Doctors : A Cross-sectional Study. BMC Public Health, 13(786), 1-8. https://doi.org/10.1186/1471-245813-786

Yusoff, M. S. B., Yee, L. Y., Wei, L. H., Siong, T. C., Hon, L., Bin, L. X., ... Rahim, A. (2011). A Study On Stress, Stressors and Coping Strategies Among Malaysian Medical Students. International Journal of Students' Research, 1(2), 45-50.

Yusoff, M. S. B., Ying Jie, T., \& Esa, A. R. (2011). Stress, stressors and coping strategies among house officers in a Malaysian hospital. ASEAN Journal of Psychiatry, 12(1), 85-94.

Zenasni, F. (2012). Burnout and Empathy in Primary Care : Three Hypotheses. British Journal of General Practice, 62(600), 346-347. https://doi.org/10.1002/pon.2115.14. 